\title{
Letrozole improves the sensitivity of breast cancer cells overexpressing aromatase to cisplatin via down-regulation of FEN1
}

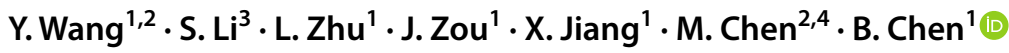

Received: 13 July 2018 / Accepted: 17 December 2018 / Published online: 2 February 2019

(c) The Author(s) 2019

\begin{abstract}
Purpose Flap endonuclease 1 (FEN1) is up-regulated by estrogen (17 $\beta$-estradiol, E2) and related to cisplatin resistance of human breast cancer cells. Letrozole, an aromatase inhibitor, suppresses the change of testosterone into estrogen and is frequently used to treat breast cancer. However, the effects of letrozole on FEN1 expression and cisplatin sensitivity in breast cancer cells overexpressing aromatase have not been revealed.

Methods The expression of FEN1 and the proteins in ERK/Elk-1 signaling were evaluated by RT-PCR and Western blot. Cisplatin sensitivity was explored through CCK-8 and flow cytometry analysis, respectively. FEN1 siRNAs and FEN1 expression plasmid were transfected into cells to down-regulate or up-regulate FEN1 expression. The promotor activity of FEN1 was detected using luciferase reporter assay.

Results FEN1 down-regulation improved cisplatin sensitivity of breast cancer cells overexpressing aromatase. Letrozole down-regulated FEN1 expression and increased cisplatin sensitivity. The sensitizing effect of letrozole to cisplatin was dependent on FEN1 down-regulation. FEN1 overexpression could block the sensitizing effect of letrozole to cisplatin. Testosterone up-regulated the promotor activity, protein expression of FEN1, and phosphorylation of ERK/Elk-1, which could be eliminated by both letrozole and MEK1/2 inhibitor U0126. Letrozole down-regulated FEN1 expression in an ERK/ Elk-1-dependent manner.

Conclusions Our findings clearly demonstrate that letrozole improves cisplatin sensitivity of breast cancer cells overexpressing aromatase via down-regulation of FEN1 and suggest that a combined use of letrozole and cisplatin may be a potential treatment protocol for relieving cisplatin resistance in human breast cancer.
\end{abstract}

Keywords Breast cancer $\cdot$ Letrozole $\cdot$ Cisplatin $\cdot$ FEN1 $\cdot$ ERK/Elk-1 signaling

Electronic supplementary material The online version of this article (https://doi.org/10.1007/s12094-018-02019-1) contains supplementary material, which is available to authorized users.

\section{Chen}

chming1971@126.com

$\triangle$ B. Chen

binnchen@tom.com

1 Department of Biochemistry and Molecular Biology, Third Military Medical University, Chongqing 400038, China

2 Department of Clinical Laboratory Medicine, Southwest Hospital, Third Military Medical University, Chongqing 400038, China

3 Department of Nephrology, Southwest Hospital, Third Military Medical University, Chongqing 400038, China

4 College of Pharmacy and Laboratory Medicine, Third Military Medical University, Chongqing 400038, China

\section{Introduction}

Current medical treatment strategies for breast cancer in clinical practice include endocrine therapy, anti-HER-2 therapy and chemotherapy [1-3]. Endocrine therapy is used for patients whose tumors express estrogen receptor (ER). Letrozole is a new generation of highly selective aromatase inhibitors (AIs) which is used for endocrine therapy. Aromatase is involved in the conversion of testosterone to estrogen and is the rate-limiting enzyme. Because AIs could inhibit the production of estrogen, they are especially used as the first-line drugs for post-menopause ER positive metastatic breast cancer, and adjunctive therapy drugs for early breast cancer [4-6]. Chemotherapy is the best therapeutic approach for patients who develop resistance to anti-HER-2 therapy and endocrine therapy. Cisplatin is a common chemotherapy drug usually used to treat breast cancer. The 
anti-cancer activity of cisplatin is involved in its binding with DNA. The formation of DNA-cisplatin complex blocks DNA replication or inhibits transcription [7, 8]. However, breast cancer cells often develop resistance to cisplatin in clinic. At present, the actual mechanisms of cisplatin resistance are not fully understood. The currently known mechanisms comprise increased DNA repair, cytosolic inactivation and altered cellular accumulation of drug [9-11]. The enhanced DNA repair ability has been demonstrated to be the key factor to result in cisplatin resistance. The increased ability of base excision repair (BER), nucleotide excision repair (NER) and mismatch repair in DNA repair pathway is considered to be involved in cisplatin resistance, and NER might be one of the most important mechanisms $[9,12]$.

FEN1 is a structure-specific endonuclease. It has flap endonuclease, gap-endonuclease activities and 5'-exonuclease $[13,14]$. These properties make it possible for FEN1 to take part in multiple pathways of DNA metabolisms, such as maintenance of telomere, stalled replication fork rescue, apoptotic DNA fragmentation and Okazaki fragment maturation $[15,16]$. FEN1 is overexpressed in multiple cancers, including metastatic prostate cancer [17], pancreatic cancer [18], neurocytoma [19] and breast cancer [20]. In breast cancer, FEN1 overexpression is considered as a potential therapy target and biomarker to monitor cancer progression $[20,21]$, and involved in resistance to a lot of chemotherapeutic drugs such as cisplatin [22-24]. Evidence suggests that FEN1 expression can be regulated by estrogen. Estrogen regulates FEN1 expression in uterine tissue whose biology is closely related to breast tissue [25]. FEN1 expression is up-regulated 2.63-fold by estrogen in MCF-7 breast cancer cells, though the exact mechanism is not clear [26]. The 5' flanking region of FEN1 includes two $\mathrm{CpG}$ islands which regulate FEN1 promoter activity, and hypomethylation of FEN1 promotor up-regulates FEN1 expression in breast cancer [20]. However, the hypomethylation mechanism can not fully explain estrogen-induced FEN1 overexpression. Estrogen-induced genes expression is generally controlled by transcriptional factor Elk-1, whose phosphorylation activity is regulated by MAPK/ERK [27, 28]. Bioinformatics analysis shows the presence of four potential Elk-1 binding sites and the absence of ER-binding sites in FEN1 promoter region. Our previous study has demonstrated that increased MAPK/ERK phosphorylation contributes to FEN1 overexpression which could be induced by cisplatin in breast cancer cells [24]. It is indicated that ERK/Elk-1 signaling may be involved in estrogen-induced FEN1 up-regulation in breast cancer cells.

In this study, the effects of letrozole on FEN1 expression and cisplatin sensitivity in breast cancer cells overexpressing aromatase were explored. We found that letrozole improved cisplatin sensitivity of MCF-7aro cells, a kind of aromatase overexpressing breast cancer cells. The sensitizing effect of letrozole to cisplatin was involved in FEN1 down-regulation through the inhibition of the ERK/Elk-1 signaling.

\section{Materials and methods}

\section{Chemicals, plasmids and antibodies}

Testosterone, letrozole and MEK1/2 inhibitor U0126 were from Sigma Chemical Co. (USA). Cisplatin was bought from Beyotime Company (China). T-ERK and p-MAPK (p44/42) were from Cell signaling technology (USA). T-Elk, p-Elk, FEN1 were from Santa Cruz Biotechnology (USA). PGL4-FP9, a luciferase reporter plasmid containing 5' flanking region of FEN1 promoter from -458 to +278 , pIRESneo and pIRES-neo-FEN1 eukaryon expression plasmid were the gifts from Dr. Binghui Shen (Beckman Research Institute, USA).

\section{Cell culture and testosterone treatment}

MCF-7aro cells were a gift from Dr. Shuian Chen (Beckman Research Institute of the City of Hope, USA) and grown at $37^{\circ} \mathrm{C}$ with $5 \% \mathrm{CO}_{2}$ in phenol-red-free MEM (GIBCO BRL, USA) containing $10 \%$ FBS (GIBCO BRL, USA), $1 \%$ NEAA (Hyclone, USA), 1\% sodium pyruvate (Hyclone, USA), $1 \%$ penicillin-streptomycin, $100 \mu \mathrm{g} / \mathrm{mL}$ G418. For testosterone treatment experiments, cells were cultured in phenol-redfree media containing 10\% charcoal-stripped FBS (Hyclone, USA) for 3 days and then treated with $10 \mathrm{nM}$ testosterone.

\section{RNA interference}

The short interfering RNA (siRNA) strand oligomers specific for FEN1 were synthesized according to the Ref. [29]. Cells were incubated in 96-well plates or six-well plates overnight, followed by transfection with FEN1 siRNA or control siRNA using the Oligofectamine ${ }^{\mathrm{TM}}$ Transfection Reagent (Invitrogen, USA) following the instructions. After $72 \mathrm{~h}$, cells in six-well plates were harvested and analyzed by Western blot. Cells in 96-well plates were used for cell proliferation assays after treatment with cisplatin for 3 days.

\section{RT-PCR}

The extraction of total RNA was performed by RNAout reagent (Beyotime, China). To produce the first-strand cDNA, $2 \mu \mathrm{g}$ of total RNA was incubated with a reverse transcriptase buffer (Takara, China). The PCR primer sequences were as follows: hFEN1, 5'-ccagctcttcttggaacctg-3' (forward); $5^{\prime}$-cgctcctcagagaactgctt-3' (reverse); GAPDH, 5'-caatgaccccttcattgacc-3' (forward); 5'-gacaagcttcccgttctcag-3' (reverse). 
PCR fragments were visualized on a $1 \%$ agarose gel stained with ethidium bromide.

\section{Western blot}

The cells were deprived of steroid for $72 \mathrm{~h}$ and serumstarved for $24 \mathrm{~h}$, followed by treatment with the agents indicated. Isolation of cell extracts and Western blot analysis was previously described [30]. GAPDH was used as a control for each group. Quantitative density of the images was calculated with the Imaging Densitometer (Model GS-700, Bio-Rad, USA) and software of Molecular Analyst (Bio-Rad, USA). The results were shown with the ratios to GAPDH density.

\section{Transient transfection and luciferase reporter assay}

MCF-7aro cells were transfected with the kit of Oligofectamine $^{\mathrm{TM}}$ Transfection Reagent (Invitrogen, USA). The number of $1.5 \times 10^{5}$ cells per well were transferred to 24-well plates and cultured overnight. A mixture of $0.2 \mu \mathrm{g}$ pGL4-FP9, $0.3 \mu \mathrm{g} \beta$-gal, $1 \mu \mathrm{L}$ Lipofectamine2000 and Opti-MEM (Invitrogen, USA) was put into each well. After incubation for $4 \mathrm{~h}$, the cells were treated with the agents indicated in serum-free medium for $24 \mathrm{~h}$. The activity of luciferase was detected with the Luciferase Assay System (Promega, USA). The activity of $\beta$-gal was detected with $\beta$-gal Assay Kit (Beyotime, China) at $420 \mathrm{~nm}$. The relative activity of luciferase was counted as dividing the activity of luciferase by $\beta$-gal.

\section{Cell proliferation assay}

Cell proliferation effect was measured by CCK-8 kit (Beyotime, China) following the instructions. Briefly, 3000-5000 cells per well (according to the experiment purpose) were seeded into 96-well plates and incubated overnight. After treatment with the agents indicated for 3 days, $10 \mu \mathrm{L}$ CCK- 8 dye was added to the well followed by incubation for $2 \mathrm{~h}$. The absorbance at $450 \mathrm{~nm}$ was detected with a microplate reader.

\section{Flow cytometry analysis}

The steroid-deprived cells were treated with testosterone, or letrozole, or cisplatin for 3 days. Then, approximately $50-60 \times 10^{4}$ cells were suspended in $1 \mathrm{~mL}$ of PBS and aspirated to obtain a mono-dispersed cell suspension. The cells were centrifuged and $900 \mu \mathrm{L}$ of the supernatant was decanted. The remaining $100 \mu \mathrm{L}$ cell suspension and $900 \mu \mathrm{L}$ of $70 \%$ ethanol were mixed and fixed for at least $48 \mathrm{~h}$, and then was analyzed with a Becton-Dickinson FACS Calibur flow cytometer.

\section{Statistical analysis}

Statistical analysis was carried out using one-way ANOVA to determine differences in means. All data were shown as mean $\pm \mathrm{SD}$, and $p<0.05$ was considered to be statistically significant.

\section{Results}

\section{FEN1 down-regulation improves MCF-7aro cells' sensitivity to cisplatin}

To examine the relationship between FEN1 expression and cisplatin sensitivity in MCF-7aro cells, RNA interference of FEN1 was first used to down-regulate FEN1 expression. FEN1 siRNA was found to obviously inhibit FEN1 expression in MCF-7aro cells (Fig. 1a, b, $p<0.05$ ). Then, the antiproliferation effect of cisplatin on cells subjected to FEN1 knockdown or not was observed (Fig. 1c and Table S1). Cisplatin inhibited the proliferation of cells treated with vehicle or cells transfected with non-specific negative control siRNA $(p<0.001)$. However, the inhibitory effect of cisplatin on cells subjected to FEN1 siRNA was more significant than control siRNA-transfected cells $(p<0.01)$. These results suggested that FEN1 down-regulation improved the sensitivity of MCF-7aro cells to cisplatin.

\section{Letrozole down-regulates the expression of FEN1 in MCF-7aro cells}

To examine the effect of letrozole on FEN1 expression in MCF-7aro cells, RT-PCR and Western blot were used to investigate the expression of FEN1 mRNA and protein in MCF-7aro cells treated with testosterone or letrozole (Fig. 2). The results showed that testosterone could upregulate mRNA and protein expression of $\operatorname{FEN} 1(p<0.01)$. Letrozole alone had no effect on FEN1 expression, because the cells were deprived of steroid. However, letrozole inhibited testosterone-induced up-regulation of FEN1 expression $(p<0.01)$. These results showed that similar to the effect of estrogen on FEN1 expression [25, 26], testosterone which was transformed into estrogen by aromatase, could also upregulate FEN1 expression and testosterone-induced FEN1 up-regulation could be blocked by letrozole.

\section{Letrozole improves MCF-7aro cells sensitivity to cisplatin}

To examine the effect of letrozole on cisplatin sensitivity in MCF-7aro cells, MCF-7aro cells were incubated in the presence or absence of testosterone with or without letrozole or cisplatin or letrozole combined with cisplatin. Then, the 
Fig. 1 FEN1 down-regulation improves MCF-7aro cell sensitivity to cisplatin. $\mathrm{Cis}$ : cisplatin. a Knockdown of FEN1 expression in MCF-7aro cells. The FEN1 siRNA or negative control siRNA was transfected into MCF-7aro cells for $24 \mathrm{~h}$, respectively. The expression of FEN1 protein was examined by Western blot. b Summarized results from a. c The antiproliferation effect of cisplatin in presence of FEN1 knockdown or not. MCF-7aro cells transfected with FEN1 siRNA or negative control siRNA were treated with or without $15 \mu \mathrm{g} /$ $\mathrm{mL}$ cisplatin for 3 days. The cell proliferation was examined by CCK-8 on 3rd day. $* p<0.05$, $* * p<0.01, * * * p<0.001$

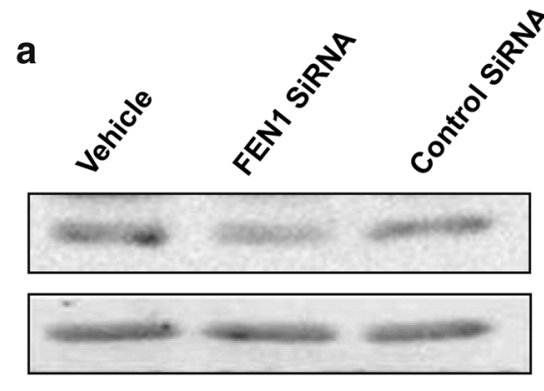

b

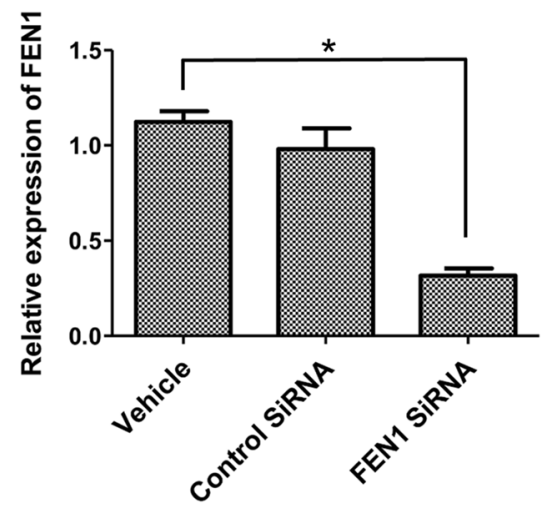

FEN1

GAPDH

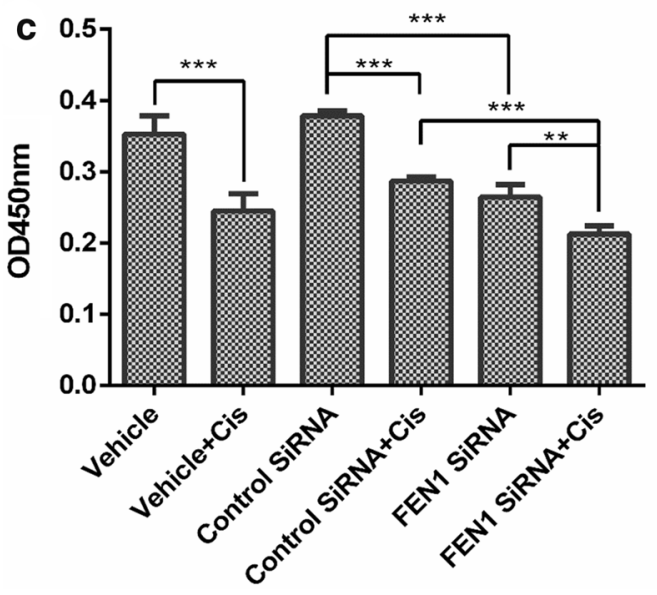

Fig. 2 Letrozole down-regulates FEN1 expression in MCF-7aro cells. Let: letrozole. T: testosterone. The cells were cultured in phenol-red-free media with $10 \%$ CD-FBS for 3 days, and then treated with $10 \mathrm{nM}$ testosterone alone or $200 \mathrm{nM}$ letrozole or $10 \mathrm{nM}$ testosterone plus $200 \mathrm{nM}$ letrozole for $24 \mathrm{~h}$. The mRNA and protein expression of FEN1 were determined by RT-PCR and Western blot. a RT-PCR analysis for FEN1 mRNA expression. GAPDH was used as an internal standard. b Summarized results from a. c Western blot analysis for FEN1 protein expression. d Summarized results from $\mathbf{c}$. $* p<0.01$

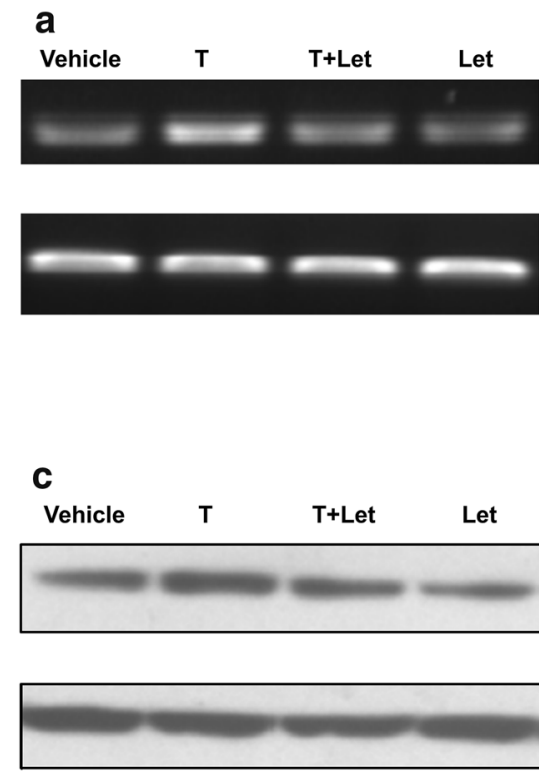

b

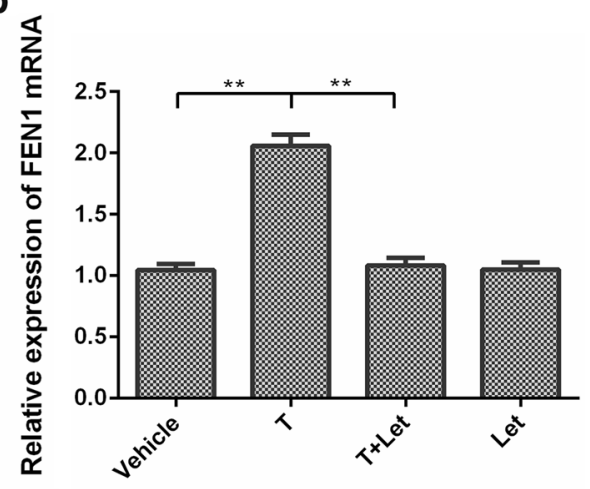

d

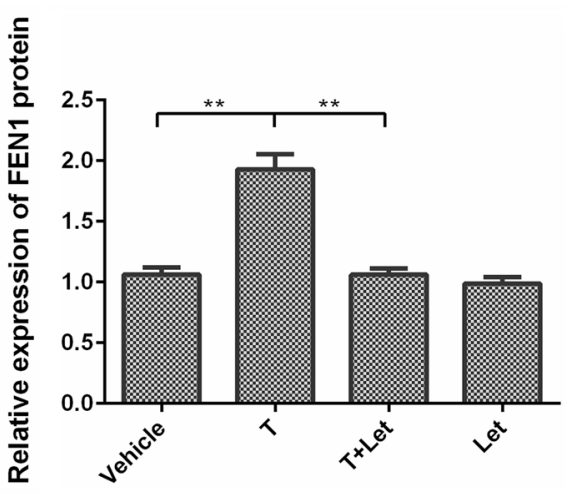


proliferation and cell cycle of treated cells were analyzed by CCK-8 analysis (Fig. 3a) and flow cytometry analysis (Table 1). The results showed that testosterone could stimulate the proliferation of MCF-7aro cells compared with vehicle $(p<0.05)$. Letrozole or cisplatin in the presence of testosterone inhibited cells proliferation compared with testosterone alone $(p<0.05)$. However, letrozole combined with cisplatin in the presence of testosterone significantly inhibited cells proliferation than letrozole or cisplatin alone $(p<0.05)$. Flow cytometry analysis showed that the proportion of cells treated with testosterone in S-phase increased compared with vehicle. The proportion of cells treated with testosterone plus letrozole and testosterone plus cisplatin in S-phase decreased compared with testosterone treatment alone. Testosterone plus letrozole combined with cisplatin markedly decreased the proportion of cells in S-phase than testosterone plus letrozole and testosterone plus cisplatin. These data suggested that letrozole improved MCF-7aro cells sensitivity to cisplatin.

\section{Letrozole improves MCF-7aro cell sensitivity to cisplatin via down-regulation of FEN1}

To confirm the relationship between the sensitization of letrozole on cisplatin and FEN1 expression in breast cancer cells, the eukaryotic-expressing plasmid of FEN1 (pIRESneo-FEN1) and control plasmid (pIRES-neo) were transfected into MCF-7aro cells, respectively. The effect of letrozole on cisplatin sensitivity in MCF-7aro cells overexpressing FEN1 was tested by CCK-8 analysis (Fig. 3b). The results showed that letrozole combined with cisplatin in MCF-7aro cells transfected with control plasmid obviously inhibited cell proliferation compared with cisplatin treatment alone, suggesting again that letrozole improves MCF-7aro cells sensitivity to cisplatin as observed in Fig. 3a. However, when FEN1 was overexpressed, the sensitization of letrozole on cisplatin disappeared. These results indicated the sensitizing effect of letrozole to cisplatin was dependent on FEN1 down-regulation and FEN1 overexpression could block the sensitizing effect of letrozole to cisplatin in MCF-7aro cells. Combined with results shown in Figs. 1 and 2, these results suggested that letrozole improved MCF-7aro cell sensitivity to cisplatin via down-regulation of FEN1 expression.

\section{Letrozole down-regulates FEN1 expression through ERK/Elk-1 signaling in MCF-7aro cells}

To explore the mechanism of letrozole to down-regulate FEN1 expression in MCF-7aro cells, the promotor activity of FEN1 and FEN1 protein expression were analyzed by luciferase reporter assay and Western blot (Fig. 4). The studies showed that testosterone stimulated the promotor activity of FEN1 and FEN1 protein expression compared with control $(p<0.05)$, which could be blocked by either letrozole or U0126. Because our previous study has demonstrated that increased MAPK/ERK phosphorylation contributes to
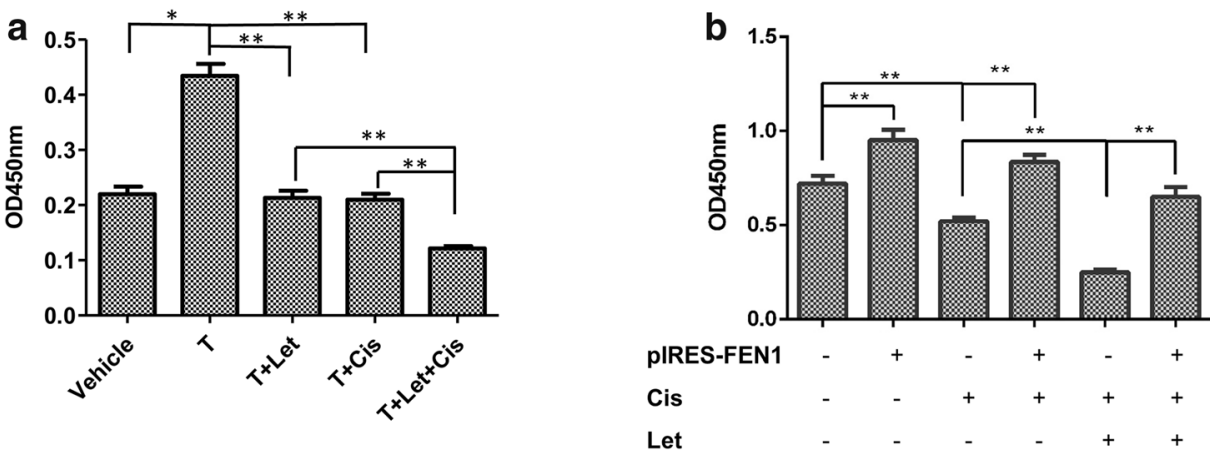

Table 1

\begin{tabular}{|c|c|c|c|c|c|}
\hline & Vehicle & T & T+Let & T+Cis & T+Let+Cis \\
\hline$\%$ of S-phase cells & $54.93 \pm 0.73$ & $63.47 \pm 1.39^{\star}$ & $40.54 \pm 2.84^{\star \star}$ & $43.56 \pm 2.03^{\star \star}$ & $35.32 \pm 0.43^{\star \star \star}$ \\
\hline
\end{tabular}

Fig. 3 Letrozole improves MCF-7aro cells sensitivity to cisplatin via down-regulation of FEN1 expression. Cis: cisplatin. Let: letrozole. T: testosterone. The cells were cultured in phenol-red-free media with $10 \%$ CD-FBS for 3 days, and then treated with or without $10 \mathrm{nM}$ testosterone alone or $10 \mathrm{nM}$ testosterone plus $200 \mathrm{nM}$ letrozole or $10 \mathrm{nM}$ testosterone plus $15 \mu \mathrm{g} / \mathrm{mL}$ cisplatin or $10 \mathrm{nM}$ testosterone plus $200 \mathrm{nM}$ letrozole plus $15 \mu \mathrm{g} / \mathrm{mL}$ cisplatin for 3 days. a Cell proliferation was measured by CCK- 8 . b MCF-7aro cells cultured in steroid-deprived media were transfected with or without pIRES-neoFEN1 or control plasmid for $24 \mathrm{~h}$, and then treated with or without $15 \mu \mathrm{g} / \mathrm{mL}$ cisplatin or $200 \mathrm{nM}$ letrozole or a combination of both for 48 h. Finally, cell proliferation was measured with CCK- 8 assay. The effect of testosterone, letrozole and cisplatin on the proportion of cells in S-phase was investigated by flow cytometry (Table 1 ). ${ }^{*} p<0.05$, $* * p<0.01, * * * p<0.001$ 
Fig. 4 The effect of testosterone, letrozole and U0126 on the promotor activity of FEN1 and FEN1 protein expression in MCF-7aro cells. Let: letrozole. $T$ : testosterone. U0126: MEK1/2 inhibitor. a The steroid-deprived cells were transfected with the FEN1 promoter plasmid and then treated with or without $10 \mathrm{nM}$ testosterone alone or $10 \mathrm{nM}$ testosterone combined with $200 \mathrm{nM}$ letrozole or $10 \mathrm{nM}$ testosterone combined with $10 \mu \mathrm{M}$ U0126 for 1 day. The FEN1 promoter activity was determined by the luciferase reporter assay. b The steroiddeprived cells were treated with or without $10 \mathrm{nM}$ testosterone alone or $10 \mathrm{nM}$ testosterone combined with $200 \mathrm{nM}$ letrozole or $10 \mathrm{nM}$ testosterone combined with $10 \mu \mathrm{M}$ U0126 for 1 day. FEN1 protein expression was examined by Western blot. c Summarized results from b. $* p<0.05, * * p<0.01$ a

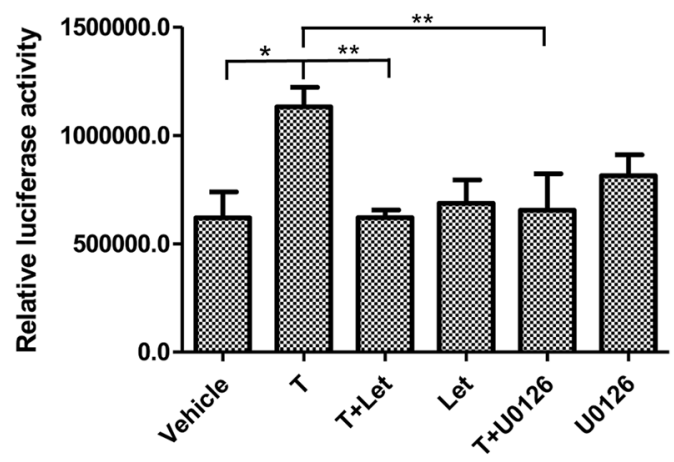

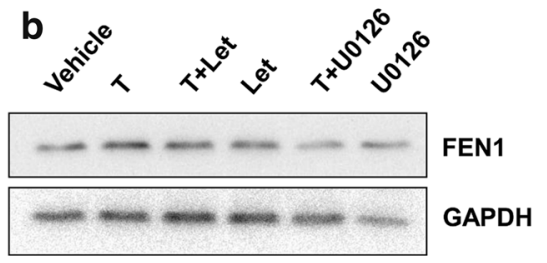

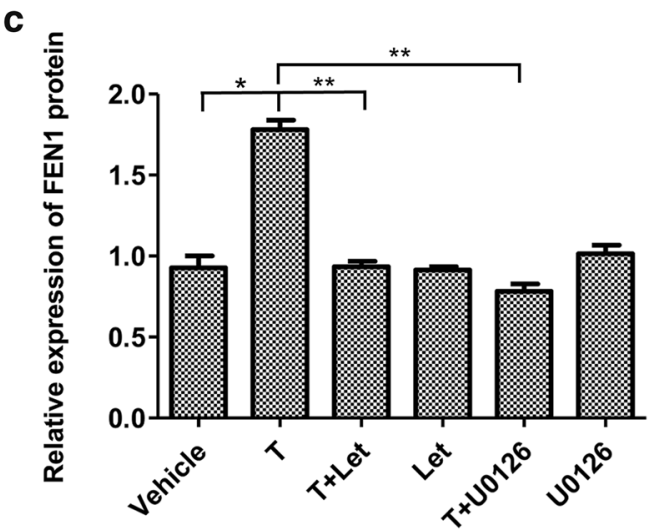

cisplatin-induced FEN1 overexpression in breast cancer cells [24], these data indicate that letrozole could down-regulated FEN1 expression in a MAPK/ERK-dependent manner. To further confirm this conclusion, the effect of testosterone, letrozole and U0126 on phosphorylation of ERK and Elk-1 were detected by Western blot (Fig. 5). The results showed that testosterone stimulated phosphorylation of ERK and Elk-1 compared with control, which could be blocked by letrozole and U0126. Taken together, these results suggested that letrozole down-regulated FEN1 expression through ERK/Elk-1 signaling.

\section{Discussion}

At present, the detailed mechanisms of cisplatin resistance in breast cancer cells remain unclear. It is urgent to search and develop new therapeutic strategies to solve cisplatin resistance for improving the treatment of breast cancer. Because FEN1 participates in DNA repair, and DNA repair mechanism, especially nucleotide excision repair mechanism plays an important role in cisplatin resistance, it indicates that FEN1 overexpression is involved in cisplatin resistance. In the LN308 glioblastoma cells, the sensitivity of cisplatin
Fig. 5 The effect of testosterone, letrozole and U0126 on phosphorylation of ERK and Elk-1 in MCF-7aro cells. T: testosterone. Let: letrozole. U0126: MEK1/2 inhibitor. a The steroid-deprived cells were pre-treated with $200 \mathrm{nM}$ letrozole and $10 \mu \mathrm{M}$ U0126 for $6 \mathrm{~h}$ and then treated with or without $10 \mathrm{nM}$ testosterone for $15 \mathrm{~min}$. The phosphorylation of ERK and Elk-1 was examined by Western blot. b Summarized results from a. $* p<0.05$, $* * p<0.01$
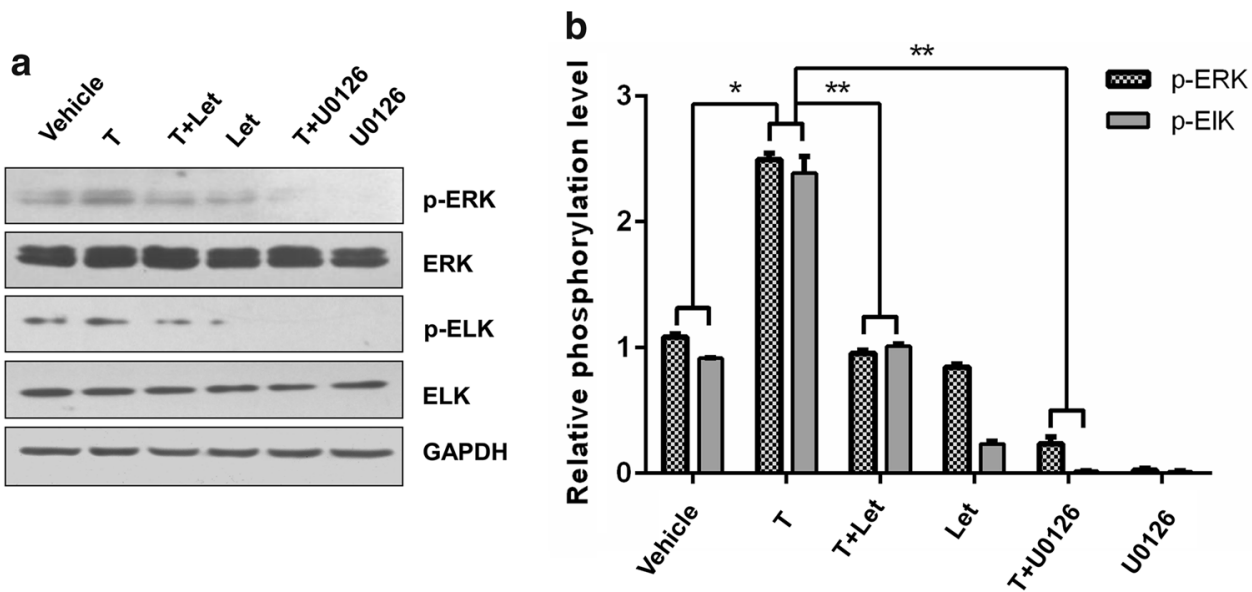
and temozolomide can be enhanced by down-regulation of FEN1 expression [31]. In breast cancer cells, the overexpression of FEN1 has also been found to cause resistance to many chemotherapy drugs [23]. Our recent research finds that FEN1 overexpression in breast cancer cells promotes cisplatin resistance [24]. In this study, similarly, our research shows that FEN1 down-regulation improves MCF-7aro cell sensitivity to cisplatin, again suggesting that FEN1 could be a potential therapeutic target to relieve cisplatin resistance in breast cancer.

It has been reported that estrogen could up-regulate FEN1 expression in breast cancer cells and FEN1 overexpression in breast cancer cells promotes cisplatin resistance [24-26]. We guess that a combination of letrozole and cisplatin may affect breast cancer cell sensitivity to cisplatin because of the anti-estrogen action of letrozole. Our current research found that testosterone up-regulated the expression of FEN1 mRNA and protein in MCF7-aro cells, which could be eliminated by letrozole. It suggests that the effect of testosterone on FEN1 expression was similar to estrogen and letrozole could inhibit FEN1 expression through blocking the transformation from androgen to estrogen. Our study further demonstrated that cisplatin combined with letrozole inhibits cell proliferation and progress of cell cycle in MCF7-aro cells better than cisplatin alone, suggesting that letrozole improves MCF7-aro cells sensitivity to cisplatin. Meanwhile, we found that FEN1 overexpression counteracted the sensitizing effect of letrozole to cisplatin, further suggesting that letrozole improves the sensitivity of breast cancer cells overexpressing aromatase to cisplatin via down-regulation of FEN1 expression.

The possible mechanism of letrozole to down-regulate FEN1 expression in MCF7-aro cells was further explored in our study. Recent research shows that the estrogen signaling is mostly affected by phosphorylation of MAPK/ ERK in the breast cancer cells $[32,33]$. The phosphorylation of ERK has been demonstrated to be associated with cisplatin resistance $[34,35]$. Our previous study has also demonstrated that increased MAPK/ERK phosphorylation contributes to cisplatin resistance and cisplatin-induced FEN1 overexpression in breast cancer cells [24]. All these accumulated evidence indicates that the phosphorylation of ERK/MAPK may be involved in letrozole-mediated FEN1 down-regulation. Our results showed that letrozole counteracted testosterone-induced FEN1 up-regulation in a MAPK/ERK-dependent manner. We further observed that testosterone-induced phosphorylation of ERK and Elk-1 could be inhibited by letrozole and U0126, suggesting that letrozole down-regulates FEN1 expression through ERK/ Elk-1 signaling. It has been reported that estrogen-mediated activation of the serum response element in MCF-7 cells through MAPK-dependent phosphorylation of Elk-1 [33]. Though we have demonstrated that increased MAPK/ERK phosphorylation contributes to cisplatin-induced FEN1 overexpression in breast cancer cells [24], it needs to be further confirmed whether testosterone-activated Elk-1 binds to FEN1 promotor.

In conclusion, letrozole improves breast cancer cells sensitivity to cisplatin via down-regulation of FEN1 expression, which is realized by inhibiting testosterone-mediated activation of ERK/Elk-1 signaling. Our research demonstrates a new mechanism of FEN1 expression regulation and provides a new strategy to overcome cisplatin resistance in breast cancer cells. Although the combination between chemotherapy and endocrinotherapy in treatment of breast cancer in clinic remains a considerable controversy, our present data suggest that a combination of letrozole and cisplatin improves cisplatin resistance in breast cancer cells.

Acknowledgements We are grateful to Dr. Shuian Chen (Department of Cancer Biology, Beckman Research Institute of the City of Hope, Duarte, CA 91010, USA) for providing MCF-7aro cells and Dr. Binghui Shen (Department of Radiation Biology, Beckman Research Institute of the City of Hope, Duarte, CA 91010, USA) for providing the FEN1 expression plasmid. This work was supported by grants from the National Natural Science Foundation of China (nos. 31571459 and 81272908).

Author contributions $\mathrm{BC}$ and $\mathrm{MC}$ are corresponding authors and organized the study. YW performed experiments. LZ and SL analyzed results. JZ and XJ edited the manuscript. All authors have read and approved the final manuscript.

\section{Compliance with ethical standards}

Conflict of interest The authors have declared that no competing interest exists.

Research involving human participants and/or animals Not applicable.

Informed Consent Informed Consent is not required for this type of study.

OpenAccess This article is distributed under the terms of the Creative Commons Attribution 4.0 International License (http://creativeco mmons.org/licenses/by/4.0/), which permits unrestricted use, distribution, and reproduction in any medium, provided you give appropriate credit to the original author(s) and the source, provide a link to the Creative Commons license, and indicate if changes were made.

\section{References}

1. Bychkovsky BL, Dizon DS, Sikov WM. Systemic therapies for nonmetastatic breast cancer: the role of neoadjuvant and adjuvant chemotherapy and the use of endocrine therapy. Clin Obstet Gynecol. 2016;59:756-71.

2. Prat A, Pineda E, Adamo B, Galvan P, Fernandez A, Gaba L, et al. Clinical implications of the intrinsic molecular subtypes of breast cancer. Breast (Edinburgh, Scotland). 2015;24(Suppl 2):S26-35. 
3. Williams CB, Soloff AC, Ethier SP, Yeh ES. Perspectives on epidermal growth factor receptor regulation in triple-negative breast cancer: ligand-mediated mechanisms of receptor regulation and potential for clinical targeting. Adv Cancer Res. 2015;127:253-81.

4. Barnadas A, Estevez LG, Lluch-Hernandez A, Rodriguez-Lescure A, Rodriguez-Sanchez C, Sanchez-Rovira P. An overview of letrozole in postmenopausal women with hormone-responsive breast cancer. Adv Ther. 2011;28:1045-58.

5. Cohen MH, Johnson JR, Justice R, Pazdur R. Approval summary: letrozole (Femara $(\mathrm{R})$ tablets) for adjuvant and extended adjuvant postmenopausal breast cancer treatment: conversion of accelerated to full approval. Oncologist. 2011;16:1762-70.

6. Santen RJ. Clinical review: effect of endocrine therapies on bone in breast cancer patients. J Clin Endocrinol Metab. 2011;96:308-19.

7. Brabec V. DNA modifications by antitumor platinum and ruthenium compounds: their recognition and repair. Prog Nucleic Acid Res Mol Biol. 2002;71:1-68.

8. Shamseddine AI, Farhat FS. Platinum-based compounds for the treatment of metastatic breast cancer. Chemotherapy. 2011;57:468-87.

9. Altaha R, Liang X, Yu JJ, Reed E. Excision repair cross complementing-group 1: gene expression and platinum resistance. Int $\mathrm{J}$ Mol Med. 2004;14:959-70.

10. Eckstein N, Haas B. Platinum-based chemotherapy in triple negative breast cancer. Dtsch Med Wochenschr. 1946;2012(137):333-6.

11. Furuta T, Ueda T, Aune G, Sarasin A, Kraemer KH, Pommier Y. Transcription-coupled nucleotide excision repair as a determinant of cisplatin sensitivity of human cells. Can Res. 2002;62:4899-902.

12. Rajewsky MF, Engelbergs J, Thomale J, Schweer T. DNA repair: counteragent in mutagenesis and carcinogenesis-accomplice in cancer therapy resistance. Mutat Res. 2000;462:101-5.

13. Nazarkina ZhK, Lavrik OI, Khodyreva SN. Flap endonuclease-1 and its role in the processes of DNA metabolism in eucaryotic cells. Mol Biol. 2008;42:405-21.

14. Zheng L, Jia J, Finger LD, Guo Z, Zer C, Shen B. Functional regulation of FEN1 nuclease and its link to cancer. Nucleic Acids Res. 2011;39:781-94.

15. Liu Y, Kao HI, Bambara RA. Flap endonuclease 1: a central component of DNA metabolism. Annu Rev Biochem. 2004;73:589-615.

16. Liu Y, Wilson SH. DNA base excision repair: a mechanism of trinucleotide repeat expansion. Trends Biochem Sci. 2012;37:162-72.

17. LaTulippe E, Satagopan J, Smith A, Scher H, Scardino P, Reuter V, et al. Comprehensive gene expression analysis of prostate cancer reveals distinct transcriptional programs associated with metastatic disease. Can Res. 2002;62:4499-506.

18. Iacobuzio-Donahue CA, Maitra A, Olsen M, Lowe AW, van Heek NT, Rosty C, et al. Exploration of global gene expression patterns in pancreatic adenocarcinoma using cDNA microarrays. Am J Pathol. 2003;162:1151-62.

19. Krause A, Combaret V, Iacono I, Lacroix B, Compagnon C, Bergeron $\mathrm{C}$, et al. Genome-wide analysis of gene expression in neuroblastomas detected by mass screening. Cancer Lett. 2005;225:111-20.

20. Singh P, Yang M, Dai H, Yu D, Huang Q, Tan W, et al. Overexpression and hypomethylation of flap endonuclease 1 gene in breast and other cancers. Mol Cancer Res MCR. 2008;6:1710-7.
21. Abdel-Fatah TM, Russell R, Albarakati N, Maloney DJ, Dorjsuren $\mathrm{D}$, Rueda OM, et al. Genomic and protein expression analysis reveals flap endonuclease 1 (FEN1) as a key biomarker in breast and ovarian cancer. Mol Oncol. 2014;8:1326-38.

22. He L, Luo L, Zhu H, Yang H, Zhang Y, Wu H, et al. FEN1 promotes tumor progression and confers cisplatin resistance in nonsmall-cell lung cancer. Mol Oncol. 2017;11:640-54.

23. Wang J, Zhou L, Li Z, Zhang T, Liu W, Liu Z, et al. YY1 suppresses FEN1 over-expression and drug resistance in breast cancer. BMC Cancer. 2015;15:50.

24. Zou J, Zhu L, Jiang X, Wang Y, Wang Y, Wang X, et al. Curcumin increases breast cancer cell sensitivity to cisplatin by decreasing FEN1 expression. Oncotarget. 2018;9:11268-78.

25. Schultz-Norton JR, Walt KA, Ziegler YS, McLeod IX, Yates JR, Raetzman LT, et al. The deoxyribonucleic acid repair protein flap endonuclease-1 modulates estrogen-responsive gene expression. Mol Endocrinol (Baltimore, Md). 2007;21:1569-80.

26. Bourdeau V, Deschenes J, Laperriere D, Aid M, White JH, Mader S. Mechanisms of primary and secondary estrogen target gene regulation in breast cancer cells. Nucleic Acids Res. 2008;36:76-93.

27. Cavalcanti FN, Lucas TF, Lazari MF, Porto CS. Estrogen receptor ESR1 mediates activation of ERK1/2, CREB, and ELK1 in the corpus of the epididymis. J Mol Endocrinol. 2015;54:339-49.

28. Mahmoodzadeh S, Dworatzek E, Fritschka S, Pham TH, RegitzZagrosek V. 17beta-Estradiol inhibits matrix metalloproteinase-2 transcription via MAP kinase in fibroblasts. Cardiovasc Res. 2010;85:719-28.

29. Holen T, Moe SE, Sorbo JG, Meza TJ, Ottersen OP, Klungland A. Tolerated wobble mutations in siRNAs decrease specificity, but can enhance activity in vivo. Nucleic Acids Res. 2005;33:4704-10.

30. Chen B, Wang Y, Kane SE, Chen S. Improvement of sensitivity to tamoxifen in estrogen receptor-positive and herceptin-resistant breast cancer cells. J Mol Endocrinol. 2008;41:367-77.

31. Nikolova T, Christmann M, Kaina B. FEN1 is overexpressed in testis, lung and brain tumors. Anticancer Res. 2009;29:2453-9.

32. Gee JM, Robertson JF, Ellis IO, Nicholson RI. Phosphorylation of ERK1/2 mitogen-activated protein kinase is associated with poor response to anti-hormonal therapy and decreased patient survival in clinical breast cancer. Int J Cancer. 2001;95:247-54.

33. Duan R, Xie W, Burghardt RC, Safe S. Estrogen receptor-mediated activation of the serum response element in MCF-7 cells through MAPK-dependent phosphorylation of Elk-1. J Biol Chem. 2001;276:11590-8.

34. Galluzzi L, Senovilla L, Vitale I, Michels J, Martins I, Kepp O, et al. Molecular mechanisms of cisplatin resistance. Oncogene. 2012;31:1869-83.

35. Wu DW, Wu TC, Wu JY, Cheng YW, Chen YC, Lee MC, et al. Phosphorylation of paxillin confers cisplatin resistance in nonsmall cell lung cancer via activating ERK-mediated Bcl-2 expression. Oncogene. 2014;33:4385-95.

Publisher's Note Springer Nature remains neutral with regard to jurisdictional claims in published maps and institutional affiliations. 